\title{
Changes in the IGF-1 and TNF-a synthesis pathways before and after three-month reduction diet with low glicemic index in women with PCOS
}

\author{
Małgorzata Szczuko', Marta Zapałowska-Chwyć ${ }^{2}$, Arleta Drozd ', Dominika Maciejewska', \\ Andrzej Starczewski ${ }^{2}$, Paweł Wysokiński ${ }^{3}$, Ewa Stachowska ${ }^{1}$ \\ ${ }^{1}$ Department of Biochemistry and Human Nutrition, Pomeranian Medical University in Szczecin, Poland \\ ${ }^{2}$ Clinic of Gynecology and Urogynecology Pomeranian Medical University in Szczecin, Poland \\ 3 Independent Laboratory of Medical Education, Pomeranian Medical University in Szczecin, Poland
}

\begin{abstract}
Objectives: An increase in IGF-I and TNF-a may be a cardioprotective effect. To examine the relationships between IGF-I and TNF- $\alpha$ and test the anthropometric and biochemical parameters before and after a low-glycemic index reduction diet using a correlation matrix.

Material and methods: Twenty-two women diagnosed with PCOS according to Rotterdam's criteria were eligible for this study, which analysed the results before and after a three months dietary intervention. Body composition measurements were determined by bioimpedance and performed twice, along with the labelling of lipid, carbohydrate and hormonal profiles. IGF-I and TNF-a were also determined in the serum.

Results: Before dietary intervention, a significant correlation was observed. A correlation was also noted between the increase in TNF-a and DHEA-SO4, FSH, glucose level and total cholesterol. The increase in IGF-I was not related to anthropometric measurements: however, its concentration was observed to be related to the level of SHBG and HDL. After dietary intervention, the correlation between TNF- $a$ and muscle mass percentage was confirmed, as was the correlation between WHR and fasting blood glucose levels. A significant negative correlation was observed between extracellular water, provided in litres, and SHBG level.

Conclusions: One important role of IGF-I in PCOS pathogenesis is the stimulation of increased synthesis of SHBG and HDL. The increased level of IGF-I after the reduction diet had a cardioprotective effect. TNF-a inhibits FSH synthesis, preventing the growth of numerous follicles. Its synthesis is also related to $\mathrm{DHEA}^{-\mathrm{SO}_{4}}$. After three-month reduction diet does not significantly reduce TNF-a.
\end{abstract}

Key words: cardioprotective effect, IGF-I, TNF-a, PCOS, reduction diet, glicemic index

Ginekologia Polska 2018; 89, 6: 295-303

\section{INTRODUCTION}

In serum, the amount of free IGF-I (insulin-like growth factor 1) does not exceed $5 \%$, and the main binding protein is IGFBP-3 [1]. Binding proteins extend the half-life and prevent hypoglycaemia induced by IGF-I. Free form IGF-I binding to a specific receptor often homologous to the insulin receptor, induces cells growth and extends their life, preventing apoptosis. IGF-l is characterized by para-and autocrynic pleiotropic activity in many tissues. Because its structure is to insulin, IGF-I has hypoglycaemic activity al- though it is weaker than in the case of insulin. The synthesis of IGF-I depends on age, sex, circadian cycles, genetic factors and chronic diseases; it correlates with menopause and bone age [2]. Studies indicate a reverse correlation between the concentration of IGF-I and body mass index (BMI) [3]. In other studies, it was observed that individuals with visceral obesity may have lower levels of IGF-I in comparison with those with the gynoid type of obesity [4]. There are numerous data supporting the involvement of IGF-I in the formation and development of malignant tumours. In some 
tumours, the level of IGF-I is regarded as a potential marker of cancerous processes [5]. Overexpression of the gene encoding for IGF-I was also observed in polycystic ovary syndrome (PCOS), where the increase in IGF-I concentration mainly because of liver synthesis intensifies the aromatization of androstenedione and testosterone from theca cells to oestradiol [3]. A positive correlation was also confirmed between circulating IGF-I and the risk of breast cancer [6]. The majority of studies seem to confirm significant involvement of IGF-I in the pathogenesis of cardiovascular diseases that are often observed in women with PCOS [7]. The role of IGF-I in the pathogenesis of these diseases is unclear because IGF-I binds to the receptor and through tyrosine kinase is involved in the cascade of reactions leading to the synthesis of NO or MAPK, which has a cardioprotective role. Studies on the understanding of the molecular mechanisms of IGF-I activity are still ongoing and can play a significant role in recognizing the aetiology of various diseases.

Research has shown that the increase in IGF-I in patients with PCOS is correlated with insulin resistance; furthermore, these patients are at a higher risk of developing breast, cervical and ovarian cancer [8]. The lack of a hormonal balance which causes disruptions between the hypothalamus pituitary gland and ovaries is also one of the causes of PCOS [9]. Silfen et al. noted that IGF-I enhances steroid cycles [10]. Moreover, IGF-I secretion depends on tumour necrosis factor (TNF-a).

TNF- $a$ is a cachectin that is mainly produced by macrophages. Its biological activity depends on its concentration. A low concentration induces autocrynic and paracrynic regulation of the immune response and at high concentrations, TNF- a has endocrynic activity [11]. The concentration of TNF- $a$ in the serum is modulated by various cytokines, hormones and soluble forms of receptors causing its neutralization [12]. Its biological role is very complex because it influences the release of prostaglandins, leukotrienes, factors activating platelets, nitrogen oxide (NO) and reactive forms of oxygen. At the same time, it is a cytokine that regulates the expression of numerous genes and has cytotoxic activity against tumour cells via ceramide cascade and cell apoptosis. TNF-a influences the processes of ovulation, fertilization and implantation of an embryo, making it an important factor in PCOS pathogenesis [13]. A higher level of androgens increases the release of TNF- $a$ from mononuclear cells (MNC) [14]. In our study, we tried to determine the effect of TNF- $a$ and IGF-I on anthropometric and biochemical parameters of patients with PCOS and the changes occurring after using a reduction diet and increased physical activity in this group of women. An increase in physical activity and the use of a reduction diet aims to reduce white adipose tissue and lower the concentration of TNF- $a$ and IL-1 in laboratory animals [15]. A positive effect of a low glikemic index Gl diet in PCOS treatment has already been suggested by other researchers [16], but the scope of our study is broader and gives an opportunity to assess metabolic changes in a wider context. Marsh et al. have demonstrated a more beneficial effect of reduction diet with low $\mathrm{Gl}$ with a reduction diet with higher glikemic index for regulating the monthly cycle of PCOS women [16].

\section{MATERIAL AND METHODS Test group}

Screening tests to diagnose PCOS were performed on 39 women with an average age of $26.76 \pm 5.08$ years old. To perform the study, the consent of the Bioethical Commission of the Pomeranian Medical University was obtained: No. KB-0012/134/12, with the addendum to the permission No. KB-0012/36/14. All patients gave written informed consent, and their confidentiality and anonymity were protected. A PCOS diagnosis was carried out based on the Rotterdam criteria, using USG (Ultrasound Voluson 730, GE, Switzerland). The test group was comprised of Caucasian women with an average body weight of $79.13 \pm 14.57 \mathrm{~kg}$ and average height of $1.67 \pm 0.06 \mathrm{~cm}$.

Measurements of body weight, height and body composition were performed using a BIA 101 device with the electric bioimpedance method (Akern, Italy). After 3-month period of the diet, three women were excluded from the study because of pregnancy, 10 women did not attend the control examination and 4 women were excluded because they did not use the diet, only the recommendations, and did not achieve the minimum body mass reduction of $2 \mathrm{~kg}$. Finally, the test group included 22 women with PCOS with a average age of $26.62 \pm 4.18$ years old. The parameters of the examined group of women with PCOS before and after the diet intervention are presented in Table 1.

\section{Biochemical measurements}

The samples were centrifuged at $3500 \mathrm{rpm}$ for $10 \mathrm{~min}$ at $4^{\circ} \mathrm{C}$ within $15 \mathrm{~min}$ of collection. The serum was transformed into $1.5 \mathrm{~mL}$ Eppendorf tubes and frozen at $-80^{\circ} \mathrm{C}$ until the analyses of TNF- $a$ and IGF-I were performed; the two parameters were measured with commercially available kits from Cayman Chemical Company (EIA Kit Item No. 589201, Ann Arbor, USA) and Quantikine ELISA R\&D Systems (Minneapolis, USA \& Canada Manufactured), respectively.

Blood for hormone analysis was collected from all of the patients in day 3-5 of the menstrual cycle. Follicle-stimulating hormone $\mathrm{mIU} / \mathrm{mL}(\mathrm{FSH})$, luteinizing hormone $\mathrm{mIU} / \mathrm{mL}$ $(\mathrm{LH})$, oestradiol $\mathrm{pg} / \mathrm{mL}\left(\mathrm{E}_{2}\right)$, testosterone $\mathrm{ng} / \mathrm{mL}(\mathrm{T})$, prolactin $\mathrm{ng} / \mathrm{mL}$ (PRL) and sex hormone-binding globulin $\mathrm{nmol} / \mathrm{L}$ (SHBG) were analysed with ECLIA (electro-chemiluminescence immunoassay), androstenedione was analysed using ELISA (Kobas Rosch E411), and DHEA-SO4 $\mu \mathrm{g} / \mathrm{dL}$ was analysed using an immunoenzymatic technique. 
Table 1. Characteristics of the test group before and after the dietary intervention

\begin{tabular}{|c|c|c|c|c|c|c|c|}
\hline \multirow{2}{*}{ Parameter } & \multicolumn{3}{|c|}{ Before } & \multicolumn{3}{|c|}{ After } & \multirow{2}{*}{$\mathbf{p}$} \\
\hline & Mean & Range & SD & Mean & Range & SD & \\
\hline $\mathrm{Na} / \mathrm{K}$ & 0.91 & $0.8-1.3$ & 0.13 & 0.92 & $0.8-1.3$ & 0.12 & NS \\
\hline TBW [\%] & 45.47 & $36.8-52.7$ & 5.25 & 47.14 & $40.9-53.6$ & 4.42 & NS \\
\hline TBW IN [\%] & 53.52 & $47.4-56.6$ & 2.45 & 53.53 & $38.9-58.3$ & 3.54 & NS \\
\hline TBW EX [\%] & 43.26 & $43.1-61.1$ & 9.27 & 46.40 & $42.6-52.7$ & 3.43 & NS \\
\hline TBW [L] & 35.57 & 29.7-50.9 & 3.99 & 34.21 & 29.7-39.9 & 3.41 & NS \\
\hline TBW IN [L] & 18.52 & $15.2-30.9$ & 2.75 & 18.29 & $12.2-23.8$ & 2.63 & NS \\
\hline TBW EX [L] & 16.48 & $14.2-25.5$ & 1.54 & 15.86 & $14.2-22.1$ & 1.53 & NS \\
\hline Phase angle PA & 5.86 & $4.7-6.6$ & 0.50 & 5.87 & $4.5-7.7$ & 0.74 & NS \\
\hline Body mass [kg] & 79.13 & $63.8-112.5$ & 14.58 & 73.01 & $61-97.5$ & 10.18 & $p<0.05$ \\
\hline fat mass [\%] & 37.92 & $27.3-47.6$ & 7.16 & 35.57 & $26.7-41.3$ & 6.06 & NS \\
\hline fat mass [kg] & 30.70 & $18.1-48.8$ & 9.72 & 26.60 & $17.2-43$ & 8.08 & $p<0.05$ \\
\hline $\mathrm{BCM}[\mathrm{kg}]$ & 24.21 & $10.7-34.3$ & 5.95 & 24.79 & $16.1-32.7$ & 3.70 & NS \\
\hline BCM [\%] & 52.93 & $40.4-56.2$ & 2.65 & 52.92 & $37.5-61.2$ & 3.77 & NS \\
\hline Muscle mass [kg] & 34.16 & $25.7-47.6$ & 6.91 & 35.39 & $23.2-54.5$ & 8.66 & NS \\
\hline Muscle mass [\%] & 41.58 & $34.6-60.7$ & 7.45 & 48.35 & $28.2-65.9$ & 9.18 & $p<0.01$ \\
\hline Waist circumference [cm] & 97.90 & $78.5-117$ & 12.13 & 90.41 & $73-107.5$ & 12.71 & $p<0.05$ \\
\hline Hip circumference [cm] & 107.89 & $96-124$ & 8.45 & 105.17 & $88.5-117$ & 9.57 & NS \\
\hline Arm circumference $[\mathrm{cm}]$ & 30.95 & $25-38$ & 3.79 & 29.36 & $22.5-39$ & 4.99 & NS \\
\hline Skinfold above ilium [mm] & 29.32 & $20.0-43.0$ & 7.32 & 23.15 & $14.0-39.0$ & 6.14 & $p<0.01$ \\
\hline Skinfold below shoulder blade [mm] & 27.26 & $12.5-36.0$ & 8.78 & 23.75 & $15.0-31.5$ & 6.93 & $p<0.05$ \\
\hline Arm skinfold [mm] & 25.62 & $13.5-37.0$ & 8.76 & 21.14 & $13.5-33.0$ & 6.85 & $p<0.05$ \\
\hline BMI $\left[\mathrm{kg} / \mathrm{m}^{2}\right]$ & 28.79 & $19.7-38.34$ & 5.56 & 26.55 & $19.5-36.25$ & 7.33 & $p<0.05$ \\
\hline WHR & 0.901 & $0.8-1.02$ & 0.07 & 0.86 & $0.72-0.95$ & 0.08 & $p<0.05$ \\
\hline DHEA-SO4 [ $\mu \mathrm{g} / \mathrm{dL}]$ & 227.78 & $112-357$ & 66.78 & 228.41 & $96-326$ & 74.44 & NS \\
\hline Androstendion ng/mL] & 4.56 & $1.5-8.2$ & 1.60 & 3.90 & $2.6-7.45$ & 1.38 & $p<0.05$ \\
\hline LH [mIU/mL] & 7.07 & $5.74-17.02$ & 1.84 & 4.97 & $2.8-8.23$ & 1.54 & $p<0.05$ \\
\hline $\mathrm{FSH}[\mathrm{mIU} / \mathrm{mL}]$ & 5.32 & $2.7-7.87$ & 1.45 & 5.26 & $2.58-7.74$ & 1.51 & NS \\
\hline Oestradiol [pg/mL] & 40.26 & $16.7-119.73$ & 14.09 & 44.69 & $20.05-69.4$ & 27.08 & NS \\
\hline SHBG [nmol/L] & 39.39 & $19.05-66.2$ & 15.94 & 44.34 & $18.1-79.9$ & 21.29 & NS \\
\hline Testosterone [ng/mL] & 0.57 & $0.28-1.3$ & 0.28 & 0.46 & $0.33-0.79$ & 0.11 & $p<0.05$ \\
\hline Prolactin [ng/mL] & 16.82 & $8.3-23.3$ & 6.11 & 13.56 & $8.7-19.6$ & 3.22 & $\mathrm{p}<0.05$ \\
\hline Insulin test 0 [mU/L] & 18.56 & $4.6-64.4$ & 16.69 & 11.38 & $4.5-17.7$ & 4.22 & $p<0.05$ \\
\hline Insulin after $\mathbf{2 h}$ [mU/L] & 68.27 & $7.2-384$ & 47.24 & 59.40 & $17.2-114.2$ & 28.01 & $p<0.05$ \\
\hline Glucose [mg/dL] & 93.07 & $84.08-106.3$ & 5.49 & 89.30 & $76.65-97.7$ & 6.10 & $p<0.05$ \\
\hline Glucose after $2 \mathrm{~h}[\mathrm{mg} / \mathrm{dL}]$ & 112.6 & $80.26-162.7$ & 23.40 & 107.85 & $59.6-151.65$ & 26.37 & NS \\
\hline Cholesterol [mg/dL] & 224.52 & $136.2-197.6$ & 25.3 & 172.45 & $142.5-194.7$ & 22.15 & $p<0.05$ \\
\hline LDL [mg/dL] & 129.37 & $78.8-150.2$ & 29.58 & 98.32 & $78.3-123.5$ & 16.45 & $p<0.01$ \\
\hline TRIGL [mg/dL] & 132.73 & $59.5-156.3$ & 39.78 & 71.2 & $53.1-139.7$ & 29.64 & $p<0.05$ \\
\hline $\mathrm{HDL}[\mathrm{mg} / \mathrm{dL}]$ & 59.13 & $34.03-103.3$ & 20.76 & 61.54 & $43.7-106.6$ & 20.02 & NS \\
\hline IGF-I [ng/mL] & 89.42 & $048-1.85$ & 0.35 & 96.988 & $0.35-1.68$ & 0.33 & $p<0.01$ \\
\hline TNF-alfa [pg/mL] & 59.69 & $35.79-104.4$ & 18.22 & 57.626 & $43.48-98.83$ & 12.32 & NS \\
\hline
\end{tabular}




\section{Dietary intervention}

Each of the participants received a 7-day diet that was individually adjusted to energy requirements and recommendations regarding lifestyle changes. The quantitative compositions of diets were calculated using Diet 4.0 software, which was recommended by National Food and $\mathrm{Nu}-$ trition Institute (NFNI). Contens energy, nutrients, minerals, vitamins dietary fibre and cholesterol, were determined. Calories in the diets were reduced by $600 \mathrm{kcal}$ with respect to energy requirements. Carbohydrate products had lowered glyceamic index (coarse grits, wholemeal products, taking into consideration vegetable fat). The sources of protein in the diet (on average 1 portion of meat and 2 portions of dairy products a day) were as follows: eggs, lean meat without skin (chicken, turkey), saltwater fish (cod, salmon, tuna), semi-skimmed pasteurized milk and dairy products (quark, natural yoghurt and buttermilk with 2\% fat). The diet included dried pulses (soy, red lentils, beans, peas).

The sources of fat (on average, 2 portions per day) were cold oils in raw form (rapeseed oil, olive oil), oily fruits, such as avocado; nuts (almonds, pumpkin seeds, sunflower seeds, sesame seeds and poppy seeds), and oily fish. The diet also included low $\mathrm{Gl}$ vegetables and fruits.

For food preparation, it was recommended to use the following heat treatment techniques: braising, roasting, cooking in water and steaming. Moreover, each patient was recommended to drink ca. 2 litres of fluid during the day. The recommended were iodized water and herbal infusions. The average weekly ratio of energy was up to $20 \%$ from protein, up to $30 \%$ from fat and ca. $50 \%$ from carbohydrates. The consumption of cod liver oil was recommended from October to April.

\section{Statistical analysis}

The results are expressed as the mean \pm standard deviation. As the distribution in most cases deviated from normal (Shapiro-Wilk test), anon-parametric Mann-Whitney test was used for comparisons between groups, and $p<0.05$ or $\mathrm{p}<0.01$ was considered statistically significant. Statistical analysis was performed with Statistica 12.0 (Statsoft, Tulsa, Oklahoma, USA) using acorrelation matrix with relation to anthropometric and biochemical parameters. The program uses basic statistics, correlation matrix, two variable lists. The correlation coefficients determined are significant at $\mathrm{p}<0.05$.

\section{RESULTS}

The correlation matrix with respect to anthropometric parameters showed a significant correlation between TNF- $a$ and the increase in total body water in the organism (TBW\%, TBW-IN\%, TBW-EX\%, TBW-litre, TBW IN litre) and body cell mass (BCM \%, $\mathrm{m}$ mass $\mathrm{kg}, \mathrm{m}$ mass \%) also manifested by arm and hip circumferences and WHR (Tab. 2). A correlation was also noted between the increase in TNF- $a$ and the following biochemical parameters: DHEA-SO4, FSH, glucose level (under fasting conditions and after 2 hours) and total

Table 2. Correlation matrix representing the correlation of IGF-I and TNF- $a$ with anthropometric and biochemical parameters before dietary intervention

\begin{tabular}{|c|c|c|}
\hline Parameter & IGF-I ng/mL & TNF-a pg/mL \\
\hline $\mathrm{Na} / \mathrm{K}$ & -0.432 & -0.079 \\
\hline TBW [\%] & 0.637 & 0.837 \\
\hline TBW IN [\%] & 0.369 & 0.767 \\
\hline TBW EX [\%] & 0.257 & 0.688 \\
\hline TBW [L] & 0.220 & 0.728 \\
\hline TBW IN [L] & 0.242 & 0.742 \\
\hline TBW EX [L] & 0.147 & 0.653 \\
\hline Phase angle PA & 0.138 & -0.010 \\
\hline Fat mass [\%] & -0.140 & 0.414 \\
\hline Fat mass [kg] & -0.308 & 0.215 \\
\hline BCM [kg] & 0.316 & 0.635 \\
\hline BCM \%] & 0.375 & 0.771 \\
\hline M mass [kg] & 0.425 & 0.904 \\
\hline M mass [\%] & 0.634 & 0.737 \\
\hline Waist circumference $[\mathrm{cm}]$ & 0.022 & 0.627 \\
\hline Hip circumference [cm] & 0.204 & 0.686 \\
\hline Arm circumference $[\mathrm{cm}]$ & 0.206 & 0.706 \\
\hline Skinfold shoulder blade [mm] & -0.301 & 0.442 \\
\hline Skinfold hip [mm] & -0.183 & 0.641 \\
\hline Skinfold arm [mm] & -0.068 & 0.520 \\
\hline WHR & 0.146 & 0.722 \\
\hline BMI $\left[\mathrm{kg} / \mathrm{m}^{2}\right]$ & 0.334 & 0.614 \\
\hline DHEA-SO4 [ $\mu \mathrm{g} / \mathrm{dL}]$ & 0.257 & 0.768 \\
\hline Androstenedione $[\mathrm{ng} / \mathrm{mL}]$ & 0.018 & 0.111 \\
\hline $\mathrm{LH}[\mathrm{mlU} / \mathrm{mL}]$ & -0.293 & 0.329 \\
\hline $\mathrm{FSH}[\mathrm{mlU} / \mathrm{mL}]$ & 0.214 & 0.683 \\
\hline Oestradiol [pg/mL] & -0.597 & 0.159 \\
\hline SHBG [nmol/L & 0.700 & 0.197 \\
\hline Testosterone [ng/mL] & 0.368 & 0.570 \\
\hline Prolactin [ng/mL] & 0.432 & 0.296 \\
\hline Insulin test $0[\mathrm{mU} / \mathrm{L}]$ & 0.239 & 0.414 \\
\hline Insulin after $2 \mathrm{~h}[\mathrm{mU} / \mathrm{L}]$ & 0.244 & 0.618 \\
\hline Glucose [mg/dL & 0.375 & 0.742 \\
\hline Glucose after $2 \mathrm{~h}[\mathrm{mg} / \mathrm{dL}$ & 0.180 & 0.848 \\
\hline Cholesterol [mg/dL] & 0.580 & 0.675 \\
\hline LDL [mg/dL] & 0.318 & 0.649 \\
\hline TRIGL [mg/dL] & -0.386 & 0.497 \\
\hline $\mathrm{HDL}[\mathrm{mg} / \mathrm{dL}]$ & 0.761 & 0.158 \\
\hline
\end{tabular}


cholesterol. An increase in IGF-I related to anthropometric measurements was not observed, but it was noted that its concentration correlated with the level of testosterone binding protein (SHBG) and HDL (Tab. 2).

After dietary intervention, the correlation between TNF- $a$ and anthropometric and biochemical parameters differed from that before the use of the reduction diet. The correlation between TNF- $a$ and \% muscle mass, WHR and fasting blood glucose level was confirmed. A significant negative correlation was also observed with relation to extracellular water (TBWEX), given in litres, and the SHBG level (Tab. 3). Correlations between IGF-I and anthropometric and biochemical parameters after the dietary intervention were as follows: IGF-I was significantly correlated with the level of testosterone and was negatively correlated with muscle mass in $\mathrm{kg}$ ( $\mathrm{m}$ mass $\mathrm{kg}$ ), upper-arm skinfold measured under the shoulder blade, skinfold measured above the crest of the ilium, and glucose level measured $2 \mathrm{~h}$ after a glucose load (Tab. 3).

\section{DISCUSSION}

\section{Correlation of IGF-I before and after dietary intervention}

An increase in IGF-I with anti-inflammatory activity through the capture of glucose and regulation of its metabolism may result from the excessive consumption of glucose and the development of obesity in women with PCOS. IGF-I also affects lipid metabolism in the organism by reducin the levels of triglycerides and free fatty acids in the serum. To summarize, the metabolic effect of IGF-I manifests by increasing the insulin sensitivity of the organism. IGF-I enhances the ability of macrophages to absorb LDL and the ability to further synthesize cytokines and chemotactic factors. Thus, its activity is pleiotropic.

Moreover, IGF-I was shown to increase the sensitivity of the ovaries to gonadotropin stimulation and indirectly affects follicle growth and oocytes maturation. It inhibits the apoptosis occurring in the follicles and thus most likely affects folliculogenesis and the proper development of the ovary. IGF-I is regarded as one of the basic factors responsible for complications in the form of nephropathy in patients with diabetes, in which the occurring proliferation of mesangial and stromal cells leads to glomerulopathy [17]. IGF-I also promotes angiogenesis in diabetic nephropathy; therefore, the drugs inhibiting the GH/IGF-I axis could be used in PCOS treatment [18].

In the case of IGF-1 before the introduction of the diet, it was correlated with only a few variables: higher concentrations of SHBG and HDL. The increase in HDL suggests a cardioprotective effect of IGF-I linked to higher synthesis with a lower concentration of the active form of testosterone. A similar correlation between HDL and IGF-I in patients
Table 3. Correlation matrix representing the correlation of IGF-I and TNF- $a$ with anthropometric and biochemical parameters after dietary intervention

\begin{tabular}{|c|c|c|}
\hline Parameter & IGF ng/mL & $\mathrm{TNF} \mathrm{pg} / \mathrm{mL}$ \\
\hline $\mathrm{Na} / \mathrm{K}$ & 0.244 & -0.209 \\
\hline TBW [\%] & 0.160 & -0.102 \\
\hline TBW IN [\%] & -0.299 & 0.325 \\
\hline TBW EX [\%] & 0.273 & -0.312 \\
\hline TBW [L] & -0.191 & -0.310 \\
\hline TBW IN [L] & -0.355 & -0.026 \\
\hline TBW EX [L] & 0.101 & -0.446 \\
\hline Phase angle PA & -0.313 & 0.304 \\
\hline Fat mass [\%] & -0.159 & 0.102 \\
\hline Fat mass [kg] & -0.230 & -0.034 \\
\hline BCM $[\mathrm{kg}]$ & -0.367 & -0.009 \\
\hline BCM [\%] & -0.296 & 0.322 \\
\hline M mass [kg] & -0.462 & 0.270 \\
\hline M mass [\%] & -0.404 & 0.497 \\
\hline Waist circumference $[\mathrm{cm}]$ & -0.189 & 0.186 \\
\hline Hip circumference $[\mathrm{cm}]$ & -0.138 & -0.176 \\
\hline Arm circumference $[\mathrm{cm}]$ & -0.377 & 0.173 \\
\hline Skinfold shoulder blade [mm] & -0.434 & 0.068 \\
\hline Skinfold hip [mm] & -0.423 & 0.045 \\
\hline Skinfold arm [mm] & 0.090 & 0.013 \\
\hline WHR & -0.190 & 0.503 \\
\hline BMI $\left[\mathrm{kg} / \mathrm{m}^{2}\right]$ & 0.354 & 0.352 \\
\hline DHEA-SO4 [ $\mu \mathrm{g} / \mathrm{dL}]$ & 0.177 & 0.040 \\
\hline Androstenedione $[\mathrm{ng} / \mathrm{mL}]$ & 0.335 & 0.221 \\
\hline $\mathrm{LH}[\mathrm{mlU} / \mathrm{mL}]$ & 0.358 & 0.304 \\
\hline $\mathrm{FSH}[\mathrm{mIU} / \mathrm{mL}]$ & -0.183 & 0.048 \\
\hline Oestradiol [pg/mL] & 0.192 & 0.186 \\
\hline SHBG [nmol/L] & 0.170 & -0.438 \\
\hline Testosterone [ng/mL] & 0.458 & -0.097 \\
\hline Prolactin [ng/mL] & 0.226 & 0.066 \\
\hline Insulin test 0 [mU/L] & 0.282 & 0.078 \\
\hline Insulin after $2 \mathrm{~h}[\mathrm{mU} / \mathrm{L}]$ & -0.256 & 0.029 \\
\hline Glucose [mg/dL] & 0.051 & 0.693 \\
\hline Glucose after $2 \mathrm{~h}[\mathrm{mg} / \mathrm{dL}]$ & -0.438 & 0.340 \\
\hline Cholesterol [mg/dL] & 0.119 & -0.094 \\
\hline LDL [mg/dL] & -0.315 & 0.099 \\
\hline TRIGL [mg/dL] & 0.267 & 0.384 \\
\hline $\mathrm{HDL}[\mathrm{mg} / \mathrm{dL}]$ & 0.376 & -0.416 \\
\hline
\end{tabular}

suffering from type II diabetes and children with metabolic syndrome was observed by other researchers [19]. However, Liang et al. speculated that IGF-1 might exert some direct or indirect effects on HDL-C metabolism. Perhaps IGF-1 inhibits the expression of class BI hepatic scavenger receptor (SRB1) 
on the surface of liver Hep2 B cells, leading to a reduction in $\mathrm{HDL}$ reverse transport and an increased circulating HDL-C concentration [20]. Another factor may influence HDL-C, at least partially, by improving the insulin sensitivity [21]. However, another cause of the correlation may be the association between IGF-1 and HDL-C driven by growth hormone (GH) [22]. Because the active form of testosterone and GH directly affect IGF-I synthesis in liver cells, it seems that the coexistence of these two factors modulates the synthesis of HDL via IGF-I.

After using the low $\mathrm{GI}$ reduction diet, a positive correlation was observed between IGF-I and testosterone, and a negative correlation was observed - between IGF-I and muscle mass (in \% and $\mathrm{kg}$ ), skinfold thickness below the shoulder blade, skinfold above the crest of the ilium, and the level of glucose after $2 \mathrm{~h}$ (OGTT). The observed correlation suggests that the synthesis of IGF-I could be affected by testosterone and improvement in glucose tolerance after a meal (OGTT). Synthesis of IGF-I was related to the reduction of visceral adipose tissue and the reduction of torso fatness because IGF-I enhances protein synthesis. It seems that in women with PCOS the basic function of OGF-I is to increase the synthesis of proteins [23], especially SHBG transporting steroid hormones (mainly testosterone) and HDL cholesterol (a fraction with the highest content of apolipoproteins) [24]. This is confirmed by the results of IGF-I correlation after the reduction diet, suggesting increased synthesis of IGF-I along with a reduction in muscle mass (in \% and kg). It also seems that the increased synthesis of IGF-I could be caused by compensation for lost muscle mass. Simultaneously, its higher level stimulated the reduction of adipose tissue in the torso, as measured by skinfold thickness and to a lesser extent in peripheral tissues. Moreover, the increased concentration of IGF-I, as a molecule similar to insulin in structure and biological activity influenced better glucose tolerance and glycaemia after a meal [25]. In diabetes, we observe a decrease in quick release insulin after a meal, when the level of glucose increases and a delayed release of insulin. Insulin increases muscle mass if accompanied by increased microcirculation and a surplus of amino acids [26]. It should be remembered that in the course of developing an inflammatory process that occurs in women with PCOS the effect of IGF-I is weakened because various cytokines inhibit its expression [27]. Therefore, an increased IGF-I level after using a reduction diet should be treated as a cardioprotective effect (Fig. 1).

\section{Correlation of TNF- $a$ before and after dietary intervention}

Observed correlations for TNF-a in women with PCOS before dietary intervention clearly relate to anthropometric parameters linked to higher testosterone activity [28]. The effect of androgens on the increase of TNF-a was also observed by Gonzalez et al [14]. Anthropometric parameters that are connected to higher testosterone level and amount of adipose tissue, which are often present in women with PCOS, can involve the following parameters relating to total body water in the organism and muscle mass: TBW \%, TBW IN\%, TBW EX\%, TBW litre, TBW IN litre, BCM \%, $\mathrm{m}$ mass kg, $\mathrm{m}$ mass $\%$ and the circumference of hip (gluteus) and arm (triceps).

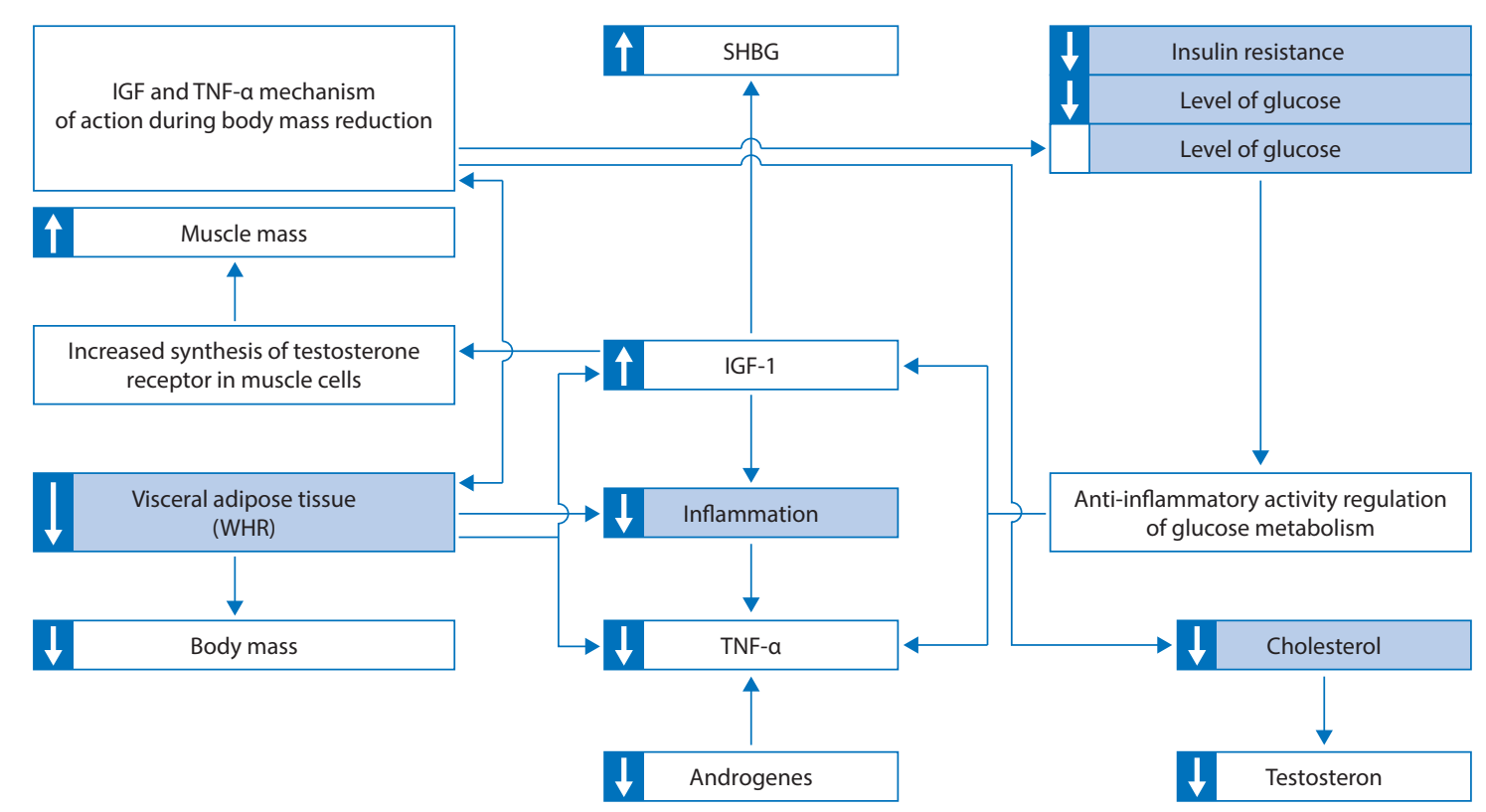

Figure 1. IGF-I and TNF-a mechanisms of action in PCOS

IGF — insulin-like growth factor 1; TNF — tumor necrosis factor a 
In our earlier study, we observed the correlation between DHEA-SO4 and TNF-a, suggesting that the mechanism of TNF-a synthesis is linked to enhancement of the $\wedge 4$ pathway [29]. Therefore, the same correlation occurring before the diet confirms our earlier observations. It should be noted that DHEA-SO4 is produced from cholesterol by the adrenal cortex via sulfation justifying the positive correlation between TNF- $a$ and the level of total cholesterol before dietary intervention.

Regarding the correlations between TNF- $a$ and hormones, it was noted that the higher level of TNF-a is related to an increased concentration of follicle-stimulating hormone (FSH). Follicle development processes are largely dependent on the stimulating effect of FSH through its receptor that is only located in granulosa cells. After reaching the size of ca. $7 \mathrm{~mm}$ in diameter, one of the follicles becomes a dominating one and develops further, whereas others die through apoptosis initiated by TNF-a in granulosa cells [30]. Thus, TNF-a has a protective function in ovary ageing because it drastically reduces FSH at the gene transcription level [31] and inhibits the synthesis of oestrogens [32].

We also observed the correlation between TNF- $a$ and WHR. A similar relationship in obese children was reported by Goral et al. However, they did not determine the direct relationship between $\mathrm{BMI}$ and the amount of adipose tissue in obese girls, similarly to our own studies [33]. The logical assumption would be that TNF-a is synthesized by macrophages in adipose tissue, visceral adipose tissue in particular [34].

After the low GI reduction diet, we also observed a positive correlation between TNF- $a$ and the level of fasting glucose, suggesting improvement in glucose tolerance after three months of the diet (because of the lack of correlation with glucose concentration $2 \mathrm{~h}$ after a meal). Positive correlations between TNF- $a$ and fasting glucose, both before and after the reduction diet, confirm the involvement of this modulator in the development of type II diabetes because of the dysfunction of the insulin receptor and reduced expression of GLUT 4 [35]. However, the results of studies performed among the obese do not confirm a significant role of TNF- $a$ in the development of insulin resistance [12].

After the reduction diet negative correlations were observed between TNF- $a$ and the level of extracellular water and SHBG. An increased level of SHBG decreased the level of active testosterone and is linked to metabolic effects of TNF-a. A lower concentration of testosterone after the diet can thus be attributed to a reduced amount of intracel-

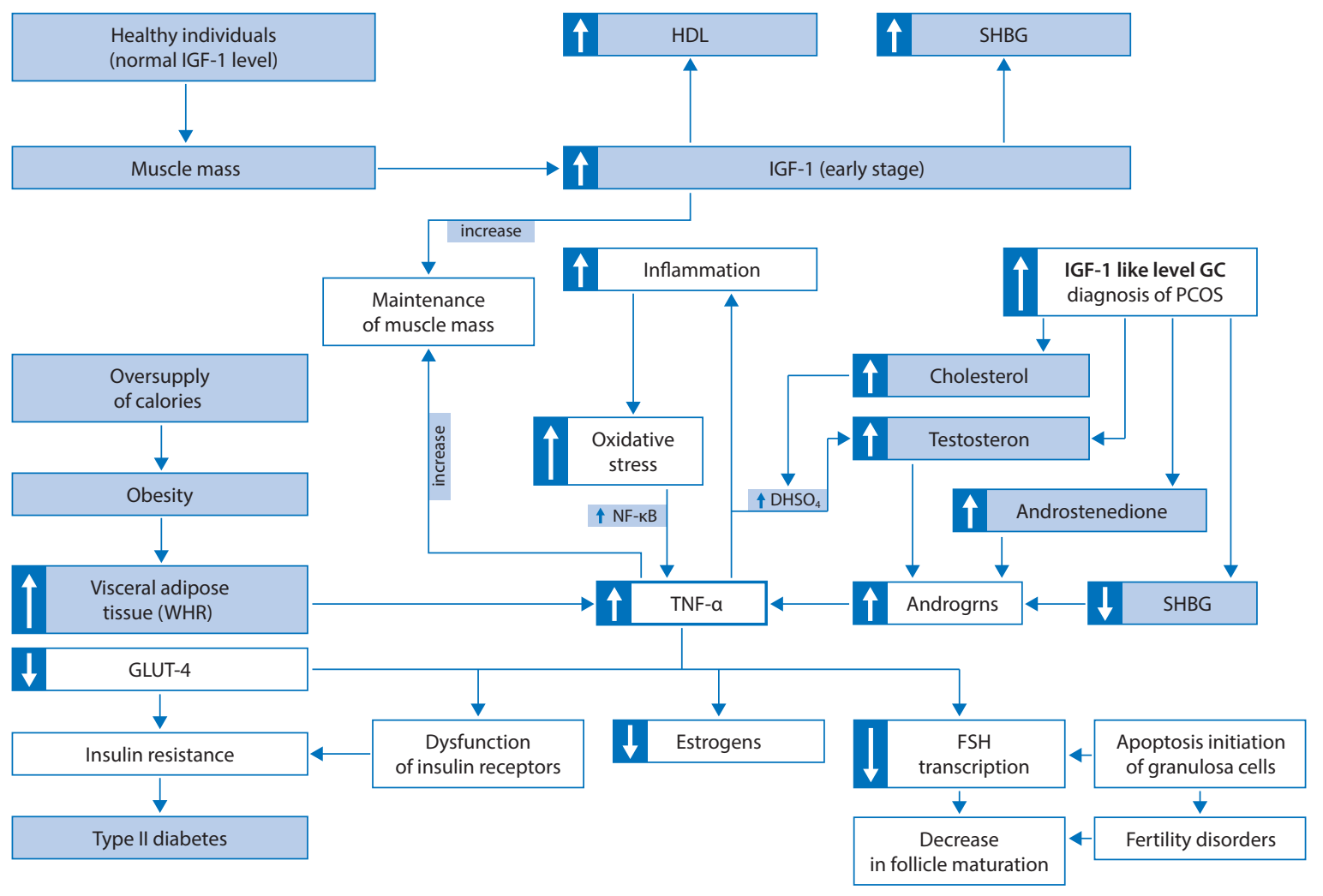

Figure 2. IGF-I and TNF-a mechanisms of action during body mass reduction

IGF-1 - insulin-like growth factor 1; TNF — tumor necrosis factor a; HDL - high-density lipoprotein; SHBG — sex hormone binding globulin; FSH — follicle-stimulating hormone; GLUT 4 - glucose transporter type 4; DHSO4 - dehydroepiandrosterone sulfate; NFkB — nuclear factor- $\mathrm{kB}$ (transcription factor) 
lular water being the result of potassium intake with the diet (on average $4421 \pm 650 \mathrm{mg} /$ day) and a reduced level of sodium in the diet (on average $1692 \pm 497 \mathrm{mg} /$ day). All of the relationships and metabolic functions of IGF-I and TNF-a in PCOS pathogenesis that are discussed above are presented in Figure 1 and Figure 2.

\section{CONCLUSIONS}

One of the major roles of IGF-I in PCOS pathogenesis is stimulation of the synthesis of SHBG and HDL. The increase of IGF-I level after the reduction diet has a cardioprotective effect. Thus, the inclusion of measuring IGF-1 and HDL levels might be warranted in the assessment protocols for obese women with PCOS to verify possible complications of early cardiovascular alterations. Enhanced synthesis of TNF-a by visceral adipose tissue in women with PCOS contributes to the development of glucose intolerance and type II diabetes. TNF-a inhibits the synthesis of FSH, disabling the growth of numerous follicles, and its synthesis is correlated with DHEA-SO4. Reduction diet does not significantly reduce synthesis TNF-a.

\section{Conflict of interest}

The authors declare that they have no conflict of interest.

\section{REFERENCES}

1. Józefiak A, Pacholska J, Kędzia W. Role of IGF-I and IGFBP in neogenesis. Rola IGF-1 i IGFBP w procesie neogenezy. Perinatologia, Neonatologia i Ginekologia. 2008; 1: 175-183.

2. Filus A, Zdrojewicz Z. Insulin-like growth factor-1 (IGF-1) - structure and the role in the human body. Pediatr Endocrinol Diabetes Metab. 2015; 20(4): 161-169, doi: 10.18544/PEDM-20.04.0016, indexed in Pubmed: 26615583.

3. Suwała A, Ziora K, Landowska D. Structure and function of insulin-like growth factors and clinical symptoms of IGF-I deficiency. Budowa i funkcja insulinopodobnych czynników wzrostowych oraz objawy kliniczne niedoboru IGF-1. Endokrynol Ped. 2010; 3: 47-62.

4. Kreitschmann-Andermahr I, Suarez P, Jennings $R$, et al. GH/IGF-I regulation in obesity--mechanisms and practical consequences in children and adults. Horm Res Paediatr. 2010; 73(3): 153-160, doi: 10.1159/000284355, indexed in Pubmed: 20197666.

5. Schmidt JA, Allen NE, Almquist $M$, et al. Insulin-like growth factor-i and risk of differentiated thyroid carcinoma in the European prospective investigation into cancer and nutrition. Cancer Epidemiol Biomarkers Prev. 2014; 23(6): 976-985, doi: 10.1158/1055-9965.EPI-13-1210-T, indexed in Pubmed: 24646451.

6. Barnes BBE, Chang-Claude J, Flesch-Janys D, et al. Cancer risk factors associated with insulin-like growth factor (IGF)-I and IGF-binding protein-3 levels in healthy women: effect modification by menopausal status. Cancer Causes Control. 2009; 20(10): 1985-1996, doi: 10.1007/s10552-0099393-0, indexed in Pubmed: 19597750.

7. Palmeiro $\mathrm{CR}$, Anand $\mathrm{R}$, Dardi IK, et al. Growth hormone and the cardiovascular system. Cardiol Rev. 2012; 20(4): 197-207, doi: 10.1097/CRD.0b013e318248a3e1, indexed in Pubmed: 22314142.

8. Druckmann R, Rohr UD. IGF-1 in gynaecology and obstetrics: update 2002. Maturitas. 2002; 41 Suppl 1:65-83, indexed in Pubmed: 11955796.

9. Schuring AN, Schulte N, Sonntag B, et al. Androgens and insulin--two key players in polycystic ovary syndrome. Recent concepts in the pathophysiology and genetics of polycystic ovary syndrome. Gynakol Geburtshilfliche Rundsch. 2008; 48(1): 9-15, doi: 10.1159/000111465, indexed in Pubmed: 18209494.

10. Silfen ME, Manibo AM, Ferin M, et al. Elevated free IGF-I levels in prepubertal Hispanic girls with premature adrenarche: relationship with hyperandrogenism and insulin sensitivity. J Clin Endocrinol Metab. 2002; 87(1): 398-403, doi: 10.1210/jcem.87.1.8143, indexed in Pubmed: 11788683.
11. Ochoa MC, Martí A, Martínez JA. Obesity studies in candidate genes. Medicina Clínica. 2004; 122(14): 542-551.

12. Goral J.TNF-alpha and carbohydrate and lipid parameters in overweight and obese children. Ann Acad Med Stetin. 2008; 54(2): 14-21, indexed in Pubmed: 19374226.

13. Guo R, Zheng Y, Yang J, et al. Association of TNF-alpha, IL- 6 and IL-1 beta gene polymorphisms with polycystic ovary syndrome: a meta-analysis. BMC Genet. 2015; 16: 5, doi: 10.1186/s12863-015-0165-4, indexed in Pubmed: 25634659.

14. González F, Sia CL, Bearson DM, et al. Hyperandrogenism induces a proinflammatory TNFa response to glucose ingestion in a receptor-dependent fashion. J Clin Endocrinol Metab. 2014; 99(5): E848-E854, doi: 10.1210/jc.2013-4109, indexed in Pubmed: 24512496.

15. Kawanishi $\mathrm{N}$, Yano H, Yokogawa Y, et al. Exercise training inhibits inflammation in adipose tissue via both suppression of macrophage infiltration and acceleration of phenotypic switching from M1 to M2 macrophages in high-fat-diet-induced obese mice. Exerc Immunol Rev. 2010; 16: 105-118, indexed in Pubmed: 20839495.

16. Marsh KA, Steinbeck KS, Atkinson FS, et al. Effect of a low glycemic index compared with a conventional healthy diet on polycystic ovary syndrome. Am J Clin Nutr. 2010; 92(1): 83-92, doi: 10.3945/ajcn.2010.29261, indexed in Pubmed: 20484445.

17. Kamenický $P$, Mazziotti G, Lombès $M$, et al. Growth hormone, insulin-like growth factor-1, and the kidney: pathophysiological and clinical implications. Endocr Rev. 2014; 35(2): 234-281, doi: 10.1210/er.2013-1071, indexed in Pubmed: 24423979.

18. Triebel J. Role of IGF-1 and glycaemic control in diabetic retinopathy. Eur J Clin Invest. 2012; 42(7): 804; author reply 805-804; author reply 806, doi: 10.1111/j.1365-2362.2012.02654.x, indexed in Pubmed: 22339364.

19. Liang $\mathrm{S}, \mathrm{Hu}$ Y, Liu C, et al. Low insulin-like growth factor 1 is associated with low high-density lipoprotein cholesterol and metabolic syndrome in Chinese nondiabetic obese children and adolescents: a cross-sectional study. Lipids Health Dis. 2016; 15: 112, doi: 10.1186/s12944-016-0275-7, indexed in Pubmed: 27343122.

20. Cao WM, Murao K, Imachi $\mathrm{H}$, et al. Insulin-like growth factor-i regulation of hepatic scavenger receptor class BI. Endocrinology. 2004; 145(12): 5540-5547, doi: 10.1210/en.2004-0330, indexed in Pubmed: 15345670.

21. Elbornsson $M, G$ Götherström $G$, Bosæus I, et al. Fifteen years of GH replacement improves body composition and cardiovascular risk factors. Eur J Endocrinol. 2013; 168(5): 745-753, doi: 10.1530/EJE-12-1083, indexed in Pubmed: 23428613.

22. Varewijck AJ, Brugts MP, Frystyk J, et al. Circulating insulin-like growth factors may contribute substantially to insulin receptor isoform $A$ and insulin receptor isoform B signalling. Mol Cell Endocrinol. 2013; 365(1): 17-24, doi: 10.1016/j.mce.2012.08.021, indexed in Pubmed: 22982059.

23. Pelosi L, Giacinti C, Nardis C, et al. Local expression of IGF-1 accelerates muscle regeneration by rapidly modulating inflammatory cytokines and chemokines. FASEB J. 2007; 21(7): 1393-1402, doi: 10.1096/fj.06-7690com, indexed in Pubmed: 17264161.

24. Di Angelantonio E, Gao P, Pennells L, et al. Emerging Risk Factors Collaboration. Lipid-related markers and cardiovascular disease prediction. JAMA. 2012; 307(23): 2499-2506, doi: 10.1001/jama.2012.6571, indexed in Pubmed: 22797450.

25. Itariu BK, Zeyda M, Prager G, et al. Insulin-like growth factor 1 predicts post-load hypoglycemia following bariatric surgery: a prospective cohort study. PLoS One. 2014; 9(4): e94613, doi: 10.1371/journal. pone.0094613, indexed in Pubmed: 24736741.

26. Pasqcal D. : Amino Acids and Proteins for the Athlete: The Anabolic Edge, Second Edition. ; 2007: 43-48.

27. Shi L, Banerjee D, Dobierzewska A, et al. Direct regulation of IGF-binding protein 1 promoter by interleukin-1 $\beta$ via an insulin- and FoxO-1-independent mechanism. Am J Physiol Endocrinol Metab. 2016; 310(8): 612623, doi: 10.1152/ajpendo.00289.2015, indexed in Pubmed: 26884383.

28. Patil CN, Wallace K, LaMarca BD, et al. Low-dose testosterone protects against renal ischemia-reperfusion injury by increasing renal IL-10-toTNF-a ratio and attenuating T-cell infiltration. Am J Physiol Renal Physiol. 2016; 311(2): F395-F403, doi: 10.1152/ajprenal.00454.2015, indexed in Pubmed: 27252490.

29. Szczuko M, Zapałowska-Chwyć M, Drozd A, et al. Effect of IGF-I and TNF-a on intensification of steroid pathways in women with PCOS phenotypes are not identical. Enhancement of progesterone pathway in women with PCOS increases the concentration of TNF-a. Gynecol Endocrinol. 2016; 32(9): 714-717, doi: 10.3109/09513590.2016.1159672, indexed in Pubmed: 26979943. 
30. Mastuda F, Inoue N, Manabe N, et al. Follicular Growth and Atresia in Mammalian Ovaries: Regulation by Survival and Death of Granulosa Cells. Journal of Reproduction and Development. 2012; 58(1): 44-50, doi: 10.1262/jrd.2011-012.

31. Nakao K, Kishi H, Imai F, et al. TNF-a Suppressed FSH-Induced LH Receptor Expression Through Transcriptional Regulation in Rat Granulosa Cells. Endocrinology. 2015; 156(9): 3192-3202, doi: 10.1210/EN.20151238, indexed in Pubmed: 26125466.

32. Ghersevich S, Isomaa V, Vihko P. Cytokine regulation of the expression of estrogenic biosynthetic enzymes in cultured rat granulosa cells. Mol Cell Endocrinol. 2001; 172(1-2): 21-30, indexed in Pubmed: 11165036.
33. Goral J, Garanty-Bogacka B, WieczorekW, et al. TNF a and selected lipid parameters in overweight and obese children and selected lipid parameters in overweight and obese children. Pediatric Endocrinology. 2004; 1(6):27-36.

34. Kang YE, Kim JiM, Joung $\mathrm{KH}$, et al. The Roles of Adipokines, Proinflammatory Cytokines, and Adipose Tissue Macrophages in Obesity-Associated Insulin Resistance in Modest Obesity and Early Metabolic Dysfunction. PLoS One. 2016; 11(4): e0154003, doi: 10.1371/journal.pone.0154003, indexed in Pubmed: 27101398.

35. Li M, Han Z, Bei W, et al. Oleanolic Acid Attenuates Insulin Resistance via NF-KB to Regulate the IRS1-GLUT4 Pathway in HepG2 Cells. Evid Based Complement Alternat Med. 2015; 2015: 1-9, doi: 10.1155/2015/643102. 